\title{
Sample Closet Medications Are Neither Novel Nor Useful
}

\author{
Kari L. Evans, BS, Steven R. Brown, MD, and Gerald W. Smetana, MD
}

Background: Many physicians dispense drug samples in their offices, but this practice may not benefit patients. We analyzed the novelty and usefulness of the medications most commonly found in sample closets in primary care practices.

Methods: In this cross-sectional study, we inventoried 10 sample closets from internal medicine and family practice offices in the Phoenix metropolitan area. We analyzed 23 medications found in 7 or more closets. To assess novelty, we determined whether the sample medication had a new mechanism of action, a generic version with the same mechanism of action on the market, and a generic medication for the same indication on the market. To assess usefulness, we determined whether the sample medication improved patient-oriented outcomes, safety, and tolerability. We noted the cost of a 1-month supply for a typical starting dose.

Results: Ninety-six percent $(n=22)$ of sample closet medications had a generic medication for the same indication and $74 \%(n=17)$ had a generic medication with the same mechanism available on the market. Only 3 medications (13\%) had evidence of superior patient-oriented outcomes when compared with other medications for the same indication. Six medications $(26 \%)$ demonstrated superior safety or tolerability. Only one medication (4\%) was recommended as a first-line therapy in an evidence-based guideline. The mean cost for a 1-month supply of a typical starting dose was $\$ 178$.

Conclusions: Sample closet medications have limited novelty and usefulness and are often expensive. The widespread use of sample medications should be reexamined. ( $\mathrm{J}$ Am Board Fam Med 2013;26: 380-387.)

Keywords: Health Policy, Practice Management, Primary Health Care, Quality of Health Care

Sample medications are commonly distributed in physician offices in the United States. In a 2009 survey, $80 \%$ of cardiologists, $70 \%$ of family physicians, and $67 \%$ of internists reported receiving

This article was externally peer reviewed.

Submitted 7 December 2012; revised 18 February 2013; accepted 22 February 2013.

From the Department of Family and Community Medicine (SRB), University of Arizona College of Medicine, Phoenix (KLE); the Banner Good Samaritan Family Medicine Residency, Phoenix, AZ (SRB); and the Division of General Medicine and Primary Care, Harvard Medical School, Boston, MA (GWS).

Funding: none.

Prior presentation: Presented at a research forum at the Society of Teachers of Family Medicine Annual Spring Conference, April 27, 2012, Seattle, WA.

Conflict of interest: SRB is a commentator for Primary Care Medical Abstracts and an associate editor for Essential Evidence. GWS has served as a consultant to Anvita Health.

Corresponding author: Steven R. Brown MD, Banner Good Samaritan Family Medicine Residency, 1300 N. 12th St., Suite 605, Phoenix, AZ 85006 (E-mail: steven.brown @bannerhealth.com). drug samples. ${ }^{1}$ Sample medications are dispensed in $20 \%$ of office encounters, ${ }^{2}$ and $12 \%$ of the US population receives drug samples annually. ${ }^{3}$ In 2004 , the pharmaceutical industry spent $\$ 16.4$ billion on the provision of sample drugs in the United States. ${ }^{3}$ Advocates argue that sample medications are convenient, provide a source of medication to patients in need, allow physicians to evaluate the effectiveness and tolerability of a medication, and allow prompt treatment. ${ }^{4}$ However, substantial evidence indicates that the use of sample medications may not benefit patients.

Physicians and office staff often use sample drugs for themselves or their families. ${ }^{5}$ Contrary to the commonly held belief that samples are used for those patients most in need, samples are used more frequently by the wealthy and insured. In a recent study, $82 \%$ of patients receiving samples were insured the entire year, and $72 \%$ of patients receiving samples had an income at least $200 \%$ above the federal poverty line. ${ }^{3}$ 
The use of sample medications that bypass office-based electronic medical records increases the risk of unintended drug interactions. A recent survey showed that physicians are concerned that dispensing of office samples bypasses counseling by pharmacists, which can help maximize therapeutic outcomes. ${ }^{6}$ Drug samples also affect physician prescribing practices and affect the cost of drugs for patients. Physicians are more likely to prescribe drugs that differ from their preferred drug choice and deviate from the usual standards of care..$^{4,7,8}$ Although patients may perceive a financial benefit from "free" sample drugs, because of subsequent prescription copayment expenses their out of pocket cost is actually higher. ${ }^{9}$

Drug samples are "almost never time worn and well-tested drugs ... and usually comprise the newest drugs on the market." ${ }^{10}$ Many new drugs on the market are "me too" drugs, a new drug within an existing class of medications that offers minimal additional therapeutic benefit. ${ }^{11}$ In addition, the long-term safety of newly approved drugs is often unknown. ${ }^{12,13}$

Newly approved drugs, including those most likely to be found in samples closets, are often not novel or useful. ${ }^{9}$ For example, in one analysis of new drugs approved by the US Food and Drug Administration (FDA) in 2008, not a single new drug was both novel and relevant to primary care. ${ }^{11}$ Many newly approved drugs are heavily marketed as samples.

To our knowledge, no prior study has inventoried sample closets and examined the novelty and usefulness of their contents. In this study, we analyze the medications most commonly found in sample closets to assess their novelty and usefulness in primary care practice.

\section{Methods}

We inventoried the drug sample closets of 10 primary care offices in the Phoenix metropolitan area. We selected a convenience sample of clinics that teach the University of Arizona College of Medicine's Longitudinal Clinical Experience curriculum and that were known to have sample closets. We inventoried 7 family medicine and 3 internal medicine offices. Six were group practices and 4 were solo practices. Five were affiliated with a hospital and 5 were private practices. We obtained signed informed consent from each practice site. The Uni- versity of Arizona College of Medicine institutional review board approved the study. We analyzed each closet on one day between November 2009 and June 2010 and for each sample medication recorded the drug name, quantity, expiration date, and dosage. We selected drugs for study if they were present in at least 7 of the 10 practice sites.

We independently assessed the novelty and usefulness of the medications, resolving differences by consensus. We established novelty by the response to 3 questions: (1) Is the medication the first in a new drug class or does it work by a novel pharmacologic mechanism? (2) Is there a generic medication with the same pharmacologic mechanism already on the market? and (3) Is there a generic medication for the same indication already on the market? Pharmacologic mechanism is defined as the mechanism by which the drug is effective; for example, rosuvastatin is a 3-hydroxy-3-methylglutaryl coenzyme A reductase inhibitor. We defined usefulness based on the answers to 4 core questions: (1) Do published randomized control trials (RCTs) or systematic reviews with patient-oriented outcomes demonstrate that the medication is superior to medications for the same indication already on the market? (2) Do comparative efficacy RCTs or systematic reviews demonstrate increased safety or tolerability compared with medications for the same condition or indication already on the market? and (3) Is the medication recommended as a first-line agent in an evidence-based guideline?

We documented the year of FDA approval, indication, and drug mechanism. For the usefulness questions, we searched MEDLINE with limits on RCTs and systematic reviews, the National Guideline Clearinghouse (www.guideline.gov), and the clinical reference tools DynaMed and Micromedex. We estimated the average wholesale price for a 1-month starting dose of each medication based on Price Alert, Drugstore.com, and the Pharmacist's Letter.

\section{Results}

The 10 sample closets contained 12,581 individual sample packets/boxes of medication, with a mean of 1258 (standard deviation, 785; range, 83-2850) per closet. The 10 closets had a mean of 123 different medications (standard deviation, 65; range, 6-241). Twenty-seven individual medications were common to at least 7 of the 10 sample closets. We 
Table 1. Characteristics of the Medications Most Commonly Found in Sample Closets and Their Costs

\begin{tabular}{|c|c|c|c|c|c|c|}
\hline $\begin{array}{l}\text { Trade } \\
\text { Name }\end{array}$ & Generic Name & $\begin{array}{l}\text { Date Initially } \\
\text { Approved by } \\
\text { FDA }\end{array}$ & $\begin{array}{c}\text { Sites } \\
\text { Containing } \\
\text { Sample (n) }\end{array}$ & Indications & $\begin{array}{l}\text { Most Common } \\
\text { Initial Dose }\end{array}$ & $\mathrm{AWP}^{*}$ \\
\hline Bystolic & Nebivolol & 2007 & 9 & Hypertension & $5 \mathrm{mg}$ daily & $\$ 68 / 30$ tabs \\
\hline Crestor & Rosuvastatin & 2003 & 9 & Hyperlipidemia & $10 \mathrm{mg}$ daily & $\$ 157 / 30$ tabs \\
\hline Januvia & Sitagliptin & 2006 & 9 & Type 2 diabetes & $100 \mathrm{mg}$ daily & $\$ 244 / 30$ tabs \\
\hline Micardis & Telmisartan & 1998 & 9 & Hypertension & $40 \mathrm{mg}$ daily & $\$ 124 / 30$ tabs \\
\hline Toviaz & Fesoterodine & 2008 & 9 & Overactive bladder & $4 \mathrm{mg}$ daily & $\$ 159 / 30$ tabs \\
\hline Avodart & Dutasteride & 2001 & 8 & $\begin{array}{l}\text { Benign prostate } \\
\text { hyperplasia }\end{array}$ & $0.5 \mathrm{mg}$ daily & $\$ 129 / 30$ tabs \\
\hline Cymbalta & Duloxetine & 2004 & 8 & Depression, anxiety & $60 \mathrm{mg}$ daily & $\$ 183 / 30$ caps \\
\hline Diovan & Valsartan & 2001 & 8 & Hypertension & $80 \mathrm{mg}$ daily & $\$ 97 / 30$ tabs \\
\hline Lipitor & Atorvastatin & 1996 & 8 & Hyperlipidemia & $20 \mathrm{mg}$ daily & $\$ 183 / 30$ tabs \\
\hline Lovaza & $\begin{array}{l}\text { Omega-3-acid ethyl } \\
\text { esters }\end{array}$ & 2004 & 8 & Hypertriglyceridemia & $4 \mathrm{~g}$ daily & $\$ 190 / 1201-g$ caps \\
\hline Pristiq & Desvenlafaxine & 2008 & 8 & Depression & $50 \mathrm{mg}$ daily & $\$ 153 / 30$ tabs \\
\hline Seroquel & Quetiapine & 1997 & 8 & $\begin{array}{l}\text { Schizophrenia, bipolar } \\
\text { disorder }\end{array}$ & $200 \mathrm{mg}$ BID & $\$ 749 / 60$ tabs \\
\hline Actos & Pioglitazone & 1999 & 7 & Type 2 diabetes & $30 \mathrm{mg}$ daily & \\
\hline Amitiza & Lubiprostone & 2006 & 7 & $\begin{array}{l}\text { Chronic idiopathic } \\
\text { constipation }\end{array}$ & $24 \mu \mathrm{g}$ BID & $\$ 272 / 60$ caps \\
\hline Celebrex & Celecoxib & 1998 & 7 & Joint pain & $100 \mathrm{mg}$ BID & $\$ 176 / 60$ caps \\
\hline Enablex & Darifenacin & 2004 & 7 & Overactive bladder & $7.5 \mathrm{mg}$ daily & $\$ 167 / 30$ tabs \\
\hline Levitra & Vardenafil & 2003 & 7 & Erectile dysfunction & $10 \mathrm{mg}$ & $\$ 21 / \mathrm{tab}$ \\
\hline Maxalt & Rizatriptan & 1998 & 7 & Migraine headache & $5 \mathrm{mg}$ & $\$ 32 / \mathrm{tab}$ \\
\hline Savella & Milnacipran & 2009 & 7 & Fibromyalgia & $50 \mathrm{mg}$ BID & $\$ 146 / 60$ tabs \\
\hline Spiriva & Tiotropium & 2004 & 7 & COPD & $\begin{array}{l}1 \text { capsule }(18 \mu g) \\
\text { daily }\end{array}$ & $\$ 289 / 30$ caps \\
\hline Synthroid & Levothyroxine & 2002 & 7 & Hypothyroidism & $100 \mu \mathrm{g}$ daily & $\$ 21 / 30$ tabs \\
\hline Trilipix & Fenofibric acid & 2008 & 7 & $\begin{array}{l}\text { Hyperlipidemia, } \\
\text { hypertriglyceridemia }\end{array}$ & $45 \mathrm{mg}$ daily & $\$ 54 / 30$ caps \\
\hline Vytorin & $\begin{array}{l}\text { Ezetimibe and } \\
\text { simvastatin }\end{array}$ & 2004 & 7 & Hyperlipidemia & $10 / 20 \mathrm{mg}$ daily & $\$ 148 / 30$ tabs \\
\hline
\end{tabular}

${ }^{*}$ Cost of a 30-day supply of the most commonly used initial dose of the medication.

AWP, average wholesale price; Cap, capsule; COPD, chronic obstructive pulmonary disease; FDA, US Food and Drug Administration; tab, tablet.

excluded 4 of these 27 medications from the study because they were combination drugs that fell into 2 separate medication classes (for example, Exforge, found in 7 sample closets, is a combination of amlodipine and valsartan). We included the medication that combines ezetimibe and simvastatin and analyzed it based on the more novel component because ezetimibe was the only novel drug in a combination medication. We also excluded nonprescription drugs $(\mathrm{n}=18)$, such as over-thecounter medications or herbal remedies, from the analysis.

We analyzed the remaining 23 medications that we found in 7 or more of the inventoried sample closets. Five sample types were present in 9 closets, 7 sample types were present in 8 closets, and 11 sample types were present in 7 closets. Table 1 lists those medications found in at least 7 of the 10 closets and the clinical indications and average monthly cost for the commonly used starting dose of each.

Figure 1 displays the proportion of the 23 medications that had novel or useful attributes on the basis of our 6 prespecified questions. Of these drugs, $78 \%(\mathrm{n}=18)$ were neither the first in a new drug class nor the first to work by a new mechanism. For $74 \%(n=17)$ of the drugs, a generic medication with the same mechanism was already on the market. In nearly all cases $(96 \% ; \mathrm{n}=22) \mathrm{a}$ generic medication for the same indication was already on the market. For $87 \%(n=20)$ of drugs, no RCTs or systemic reviews with patient-oriented outcomes demonstrated superiority to medications 
Figure 1. Percentage of yes and no answers regarding novelty and usefulness of most commonly found sample drugs. RCT, randomized control trials.

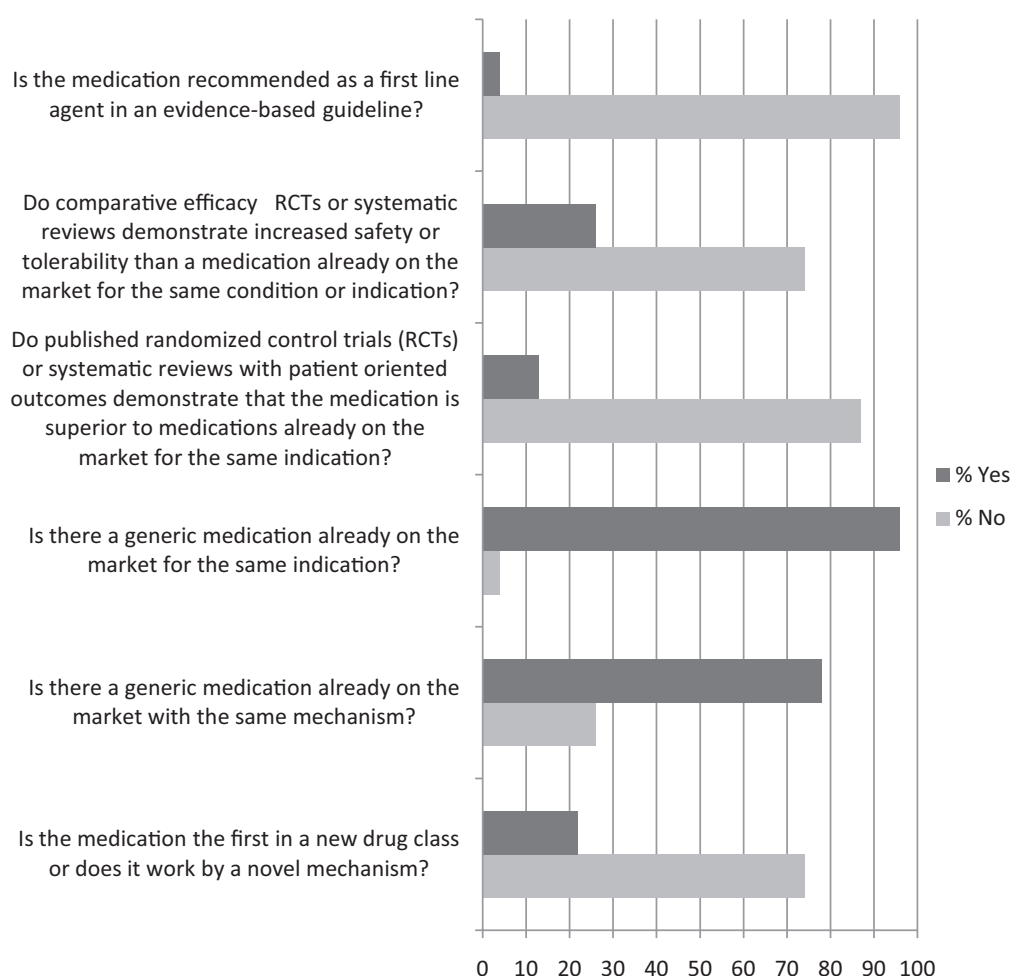

$\begin{array}{lllllllllll}0 & 10 & 20 & 30 & 40 & 50 & 60 & 70 & 80 & 90 & 100\end{array}$

for the same indication that were already on the market. For $74 \%(n=17)$ of the medications, no published RCTs or systemic reviews demonstrated superior safety or tolerability. One $(4 \%)$ of the medications is recommended as first-line therapy in an evidence-based guideline. Table 2 shows the guideline used to evaluate each medication.

The average wholesale price for 1 month of the most commonly used starting dose for each analyzed drug is shown in Table 1. One drug, atorvastatin, is now available as a generic; however, the average wholesale price is listed for the branded drug since the branded drug was found in sample closets. The mean cost of a 1 month supply of the most commonly used starting dose for each of the 23 analyzed drugs was $\$ 178$, with a median of $\$ 158$, minimum of $\$ 21$, and maximum of $\$ 749$. In 20 of 23 instances, a generic alternative was available at a commonly used pharmacy for $\$ 4$ per month. ${ }^{28}$

\section{Discussion}

In this study, we found that the medications most commonly found in drug sample closets are rarely novel or useful and are expensive. Only 5 of the 23 medications are the first in a new class of medica- tions. The remainder of the medications are "me too" drugs, that is, medications in the same drug class as an existing medication that offer little additional benefit. ${ }^{29}$ For example, the 3-hydroxy-3methylglutaryl coenzyme A reductase inhibitors rosuvastatin and atorvastatin were found in 9 and 8 sample closets, respectively. These drugs are among 8 "statin" drugs on the market, including 3 that are currently available as generics. ${ }^{29}$ All medications except one, vardenafil, have a generic drug for the same indication available on the market.

In addition, commonly sampled medications are often not useful. To be useful, a medication should be safer or more effective than existing medications as indicated in comparative effectiveness studies. Evidence for greater efficacy would come from patientoriented outcomes such as morbidity, mortality, and quality of life rather than surrogate, or proxy, markers. In our study, for 20 of the 23 sample closet medications, no studies demonstrated superior patient-oriented outcomes. This is not surprising. The FDA commonly approves drugs based on improvements in a surrogate marker (eg, blood pressure). Although studies of clinically meaningful outcome measures may exist, they commonly compare the 
Table 2. Medications Most Commonly Found in Sample Closets and the Relevant Guideline to Evaluate Usefulness

\begin{tabular}{|c|c|c|}
\hline Trade Name & Generic name & $\begin{array}{l}\text { Relevant } \\
\text { Guideline }\end{array}$ \\
\hline Synthroid & Levothyroxine & AACE $2002^{14}$ \\
\hline Maxalt & Rizatriptan & $\begin{array}{l}\text { AAFP/ACP-ASIM } \\
2002^{15}\end{array}$ \\
\hline Levitra & Vardenafil & ACP $2010^{16}$ \\
\hline Celebrex & Celecoxib & ACR $2012^{17}$ \\
\hline Januvia & Sitagliptin & ADA $2012^{18}$ \\
\hline Actos & Pioglitazone & ADA $2012^{18}$ \\
\hline Cymbalta & Duloxetine & APA $2010^{19}$ \\
\hline Pristiq & Desvenlafaxine & APA $2010^{19}$ \\
\hline Amitiza & Lubiprostone & ASCRS $2007^{20}$ \\
\hline Lovaza & $\begin{array}{l}\text { Omega-3-acid ethyl } \\
\text { esters }\end{array}$ & ATP III $2004^{21}$ \\
\hline Crestor & Rosuvastatin & ATP III $2004^{21}$ \\
\hline Lipitor & Atorvastatin & ATP III $2004^{21}$ \\
\hline Trilipix & Fenofibric Acid & ATP III $2004^{21}$ \\
\hline Vytorin & $\begin{array}{c}\text { Ezetimibe and } \\
\text { simvastatin }\end{array}$ & ATP III $2004^{21}$ \\
\hline Avodart & Dutasteride & $\mathrm{AUA}^{22}$ \\
\hline Savella & Milnacipran & EULAR $2008^{23}$ \\
\hline Spiriva & Tiotropium & GOLD $2010^{24}$ \\
\hline Bystolic & Nebivolol & $\mathrm{JNC} \mathrm{VII}^{25}$ \\
\hline Micardis & Telmisartan & $\mathrm{JNC} \mathrm{VII}^{25}$ \\
\hline Diovan & Valsartan & $\mathrm{JNC} \mathrm{VII}^{25}$ \\
\hline Toviaz & Fesoterodine & NICE $2006^{26}$ \\
\hline Enablex & Darifenacin & NICE $2006^{26}$ \\
\hline Seroquel & Quetiapine & NICE $2006^{27}$ \\
\hline
\end{tabular}

AACE, American Association of Clinical Endocrinologists; AAFP, American Academy of Family Physicians; ACP-ASIM, American College of Physicians-American Society of Internal Medicine; ADA, American Diabetes Association; ACR, American College of Rheumatism; APA, American Psychiatric Association; ASCRS, American Society of Colon and Rectal Surgeons; ATP, Adult Treatment Panel; AUA, American Urologic Association; EULAR, European League Against Rheumatism; GOLD, Global Initiative for Chronic Obstructive Lung Disease; JNC, Joint National Committee; NICE, National Institute for Clinical Excellence (UK).

drug only to placebo rather than to existing medications. $^{30}$

Superior safety or tolerability data existed for only $26 \%$ of the sample closet drugs. Even this figure may actually overstate the incremental benefit of the sampled medications. Often, the incremental improvement in tolerability or safety existed only in a limited number of industry-funded studies. In no instance did the evidence base indicate that a sample closet medication was safer or better tolerated than every available alternative medica- tion. If a new medication improves neither patientoriented outcomes nor tolerability, its usefulness is limited.

The medications found most commonly in sample closets are rarely first-line agents according to published guidelines. Clinical practice guidelines are "statements that include recommendations intended to optimize patient care that are informed by a systematic review of evidence and an assessment of the benefits and harms of alternative care options." ${ }^{31}$ In each instance, we identified a guideline that pertained to the indication for the particular sample closet medication. For example, the Joint National Committee 7 guidelines for the evaluation and treatment of hypertension $^{25}$ address the 3 medications approved for hypertension (nebivolol, telmisartan, and valsartan) and the National Institute for Clinical Excellence overactive bladder guideline ${ }^{26}$ discusses the 2 medications approved for that indication (fesoterodine and darifenacin). Several medications are listed among guideline options, such as rizatriptan for migraine, but often a generic is also listed as an option in the guidelines. We determined that one medication, Synthroid (levothyroxine), is a first-line treatment for the approved condition based on a national guideline. However, its generic version, levothyroxine, is equivalent $^{32}$ and less expensive.

When compared with generic medications, sample closet medications are expensive: the cost was as high as $\$ 749$ per month, while the mean was $\$ 178$ per month. Many applicable generics are available at low cost—as low as $\$ 4$ per month in selected "big box" and retail pharmacies. After a supply of "free" samples is depleted, a patient often will continue the same medication at a higher cost to both the patient and the health care system. ${ }^{9}$ In addition to the patient-level cost, the use of expensive medications costs the US health system billions of dollars annually. ${ }^{10}$ For example, the use of brand-name cholesterol-lowering medications, instead of generics, costs the US health care system $\$ 5.8$ billion dollars annually. ${ }^{33}$ In addition, nonadherence is common when the cost to the patient is high; this has the potential to increase morbidity. ${ }^{34-36}$

There are several limitations to our study. First, it is a small cross-sectional study in one metropolitan area over one period of time. It is possible that the closets we inventoried during this time frame are not representative of sample closets nationwide. Further study should include inventories of sample closets across a greater variety of practices nation- 
wide in both urban and rural as well as academic and private practice settings. In addition, it is not known whether these samples are representative of the entire year. The wide standard deviation of the number of drugs in each sample closet indicates that the inventory of more closets could be useful. Additional and larger studies could lead to a better understanding of the novelty and usefulness of sample closet medications and improve generalizability. Second, the 6 questions we selected to analyze the novelty and usefulness of the sample medications could be an oversimplification. Estimates of novelty and usefulness based on our questions may have been biased in unforeseen ways. In particular, we had thoroughly reviewed the literature and hypothesized that samples were not likely to be novel or useful. We included a nationally recognized expert on novelty and usefulness of new medications (GWS) in our author group to minimize this observer bias. Finally, while we performed a careful search of the literature to identify relevant practice guidelines, it is possible that we have overlooked guidelines that would have changed some of our conclusions.

On the basis of compelling evidence that sample medications are often no safer or more effective than less expensive alternatives, many have called for the cessation of the distribution of samples. ${ }^{10,37-40}$ Indeed, many physicians already have chosen to close their sample closets; the number of physicians accepting samples has decreased from $78 \%$ in 2004 to $64 \%$ in 2009. ${ }^{1}$ Many academic medical centers and residency training programs prohibit the use of samples. ${ }^{10,41}$

Sample closets also require considerable maintenance and are subject to increasingly complex regulatory requirements. A physician or member of the office staff must organize the samples, dispose of expired medications, and accurately track sample distribution. ${ }^{42,43}$ Drugs in sample closets are often expired, leading to a potential for decreased therapeutic efficacy and an estimated waste of $\$ 2$ billion annually. ${ }^{44}$

What are the alternatives to a sample closet? Physicians should consider nonpharmacologic treatment strategies when possible. When a medication is appropriate, physicians should consult both local institutional formularies and evidence-based guidelines that emphasize low-cost generics. ${ }^{36}$ Erickson and Cullison $^{38}$ have proposed a low-cost, physiciansponsored closet of generic medications for patients in need. "Counter detailing," evidence-based prescribing advice in an office setting by nonconflicted local and national experts, provides an alternative to pharmaceutical detailing. ${ }^{45-47}$

There are some instances where thoughtful, evidence-based use of medications that can be accessed immediately may be considered in select populations, such as the underserved. In some cases, as with inhalers for asthma, there are no drugs available on the low-cost generic list. Alternatives to sample closet medications need to be considered carefully for patients who may not have adequate access to medication. Even in uninsured populations, samples should be used with caution because they may lead to worse outcomes in select conditions. ${ }^{48}$ The availability and usefulness of sample closet medications among the underserved deserves further study.

Sample closet medications most often are no safer and are neither novel nor more effective than existing generic alternatives. Sample closet medications also increase the cost to both the patient and society. Guideline-based prescribing increases the use of medications that have a longer track record of safety and efficacy. The time has come to reexamine the use of sample closets.

The authors thank Michelle Agresti, PharmD, Clinical Pharmacist, Beth Israel Deaconess Physician Organization, who consulted on drug prices.

\section{References}

1. Campbell EG, Rao SR, DesRoches CM, et al. Physician professionalism and changes in physician-industry relationships from 2004-2009. Arch Int Med 2010;170:1820-6.

2. Backer EL, Lebsack JA, Van Tonder RJ, Crabtree $\mathrm{BF}$. The value of pharmaceutical representative visits and medication samples in community-based family practices. J Fam Pract 2000;49:811-6.

3. Cutrona SL, Woolhandler S, Lasser KE, Bor DH, McCormick D, Himmelstein DU. Characteristics of recipients of free prescription drug samples: a nationally representative analysis. Am J Public Health 2008;98:284-9.

4. Chew LD, O'Young TS, Hazlet TK, Bradley KA, Maynard C, Lessler DS. A physician survey of the effect of drug sample availability on physicians' behavior. J Gen Intern Med 2000;15:478-83.

5 Westfall JM, McCabe J, Nicholas RA. Personal use of drug samples by physicians and office staff. JAMA 1997;278:141-3. 
6. Aseeri MA, Miller DR. Patient education and counseling for drug samples dispensed at physicians' offices. J Am Pharm Assoc 2003;46:621-3.

7. Symm B, Averitt M, Furjuoh SN, Preece C. Effects of using free sample medications on the prescribing practices of family physicians. J Am Board Fam Med 2006;19:443-9.

8. Adair RF, Holmgen LR. Do drug samples influence resident prescribing behavior? A randomized trial. Am J Med 2005;118:881-4.

9. Alexander GC, Zhang J, Basu A. Characteristics of patients receiving pharmaceutical samples and association between sample receipt and out-of-pocket prescription costs. Med Care 2008;46:394-402.

10. Chimonas S, Kassirer JP. No more free drug samples? PLoS Med 2009;6:e10000074.

11. Smetana GW, Sillman JS. Update in new medications for primary care. J Gen Intern Med 2009;24: 111-7.

12. Anderson GM, Juurlink D, Detsky AS. Newly approved does not always mean new and improved. JAMA 2008;299:1598-600.

13. Friedman MA, Woodcock J, Lumpkin MM, Shuren JE, Hass AE, Thompson LJ. The safety of newly approved medicines: do recent market removals mean there is a problem? JAMA 1999;281:1728-34.

14. Baskin HJ, Cobin RH, Duick DS, et al. American Association of Clinical Endocrinologists medical guidelines for clinical practice for the evaluation and treatment of hyperthyroidism and hypothyroidism. Endocr Pract 2002;8:457-69.

15. Snow V, Weiss K, Wall EM, Mottur-Pilson C; American Academy of Family Physicians; American College of Physicians-American Society of Internal Medicine. Pharmacologic management of acute attacks of migraine and prevention of migraine headaches. Ann Intern Med 2002;137:840-9.

16. Qaseem A, Snow V, Denberg TD, et al. Hormonal testing and pharmacologic treatment of erectile dysfunction: a clinical practice guideline from the American College of Physicians. Ann Intern Med 2009; 151:639-49.

17. Hochberg MC, Altman RD, April K, et al. American College of Rheumatology 2012 recommendations for the use the nonpharmacologic and pharmacologic therapies in osteoarthritis of the hand, hip, and knee. Arthritis Care Res (Hoboken) 2012;64:465-74.

18. American Diabetes Association. Standards of medical care in diabetes 2012. Diabetes Care 2012;35: S11-63.

19. American Psychiatric Association (APA). Practice guideline for the treatment of patients with major depressive disorder. 3rd ed. Arlington: APA; 2010.

20. Ternent CA, Bastawrous AL, Morin NA, et al.; The Standards Practice Task Force of the American Society of Colon and Rectal Surgeons. Practice parameters for the evaluation and management of constipation. Dis Colon Rectum 2007;50:2013-22.
21. Grundy SM, Cleeman JI, Merz CN, et al.; National Heart, Lung, and Blood Institute; American College of Cardiology Foundation; American Heart Association. Implications of recent clinical trials for the National Cholesterol Education Program Adult Treatment Panel III guidelines. Circulation 2004; 110:227-39.

22. McVary KT, Roehrborn CG, Avins BL, et al. Update on AUA guideline on the management of benign prostatic hyperplasia. J Urol 2011;185:1793803.

23. Carville SF, Arendt-Nielsen S, Blotman F, et al. EULAR evidence-based recommendations for the management of fibromyalgia syndrome. Ann Rheum Dis 2008;67:536-41.

24. Global Initiative for Chronic Obstructive Lung Disease (GOLD). Global strategy for the diagnosis, management, and prevention of chronic obstructive pulmonary disease. Bethesda: GOLD; 2010.

25. Chobanian AV, Bakris GL, Black HR, et al. Seventh report of the Joint National Committee on Prevention, Detection, Evaluation, and Treatment of High Blood Pressure. Hypertension 2003;42:1206-42.

26. National Institute for Health and Care Excellence. Urinary incontinence: the management of urinary incontinence in women. Available from: http://www. nice.org.uk/cg40. Accessed April 25, 2012.

27. National Institute for Health and Care Excellence. The management of bipolar disorder in adults, children, and adolescents, in primary and secondary care. Available from: www.nice.org.uk/cg038. Accessed April 30, 2012.

28. Target Pharmacy. \$4 Generic drugs listed by condition. Available from: http://sites.target.com/site/en/spot/ page.jsp?title $=$ pharmacy_generic_drugs_condition. Accessed April 25, 2012.

29. Gagne JJ, Choudhry NK. How many "me-too" drugs is too many? JAMA 2011;305:711-12.

30. Goldberg NH, Schneeweiss S, Kowal MK, Gagne JJ. Availability of comparative efficacy data at the time of drug approval in the United States. JAMA 2011; 305:1786-9.

31. Institute of Medicine. Clinical practice guidelines we can trust. March 23, 2011. Available from: http://www. iom.edu/Reports/2011/Clinical-Practice-GuidelinesWe-Can-Trust.aspx. Accessed April 25, 2012.

32. Dong BJ, Hauck WW, Gambertoglio JG, et al. Bioequivalence of generic and brand-name levothyroxine products in the treatment of hypothyroidism. JAMA 1997;277:1205-13.

33. Kale MS, Bishop TF, Federman AD, Keyhani S. "Top 5" lists top \$5 billion. Arch Intern Med 2011; 171:1856-8.

34. Piette JD, Heisler M, Wagner TH. Cost-related medication underuse: do patients with chronic illnesses tell their doctors? Arch Intern Med 2004;164: $1749-55$. 
35. Madden JM, Graves AJ, Zhang F, et al. Cost-related medication nonadherence and spending on basic needs following implementation of Medicare Part D. JAMA 2008;299:1922-8.

36. Sagall RJ. Can your patients afford the medications you prescribe? Fam Pract Manag 2006;13:67-9.

37. Brown SR. Closing the sample closet. Fam Pract Manag 2006;13:16-21.

38. Erickson SH, Cullison S. Closing the sample closet. Fam Pract Manag 1995;October:43-47.

39. Brennan TA, Rothman DJ, Blank L, et al. Health industry practices that create conflicts of interest: a policy proposal for academic medical centers. JAMA 2006;295:429-33.

40. Puget Sound Health Alliance. Position statement on use of pharmaceutical samples in practice locations. Available from: http://www.pugetsoundhealthalliance. org/services/documents/HealthAlliancePosition RxSamples_053006.pdf. Accessed April 25, 2012.

41. Fugh-Berman A, Brown SR, Trippett R, et al. Closing the door on pharma? A national survey of family medicine residencies regarding industry interactions. Acad Med 2011;86:649-54.
42. Hall KB, Tett SE, Nissen LM. Perceptions of prescription medicine samples on prescribing by family physicians. Med Care 2006;44:383-7.

43. Cohen ML. Taming the sample closet. Fam Pract Manag 2006;13:43-6.

44. Evans KL, Brown SR. Many sample closet medications are expired. J Am Board Fam Med 2012;25: 394-5.

45. O'Brien MA, Rogers S, Jamtvedt G, et al. Educational outreach visits: effects on professional practice and health care outcomes. Cochrane Database Syst Rev 2007;(4):CD000409.

46. Allen M, Ferrier S, O'Connor N, Fleming I. Family physicians' perception of academic detailing: a quantitative and qualitative study. BMC Med Educ 2007;7:36.

47. Avorn J. Teaching clinicians about drugs-50 years later, whose job is it? N Engl J Med 2011;364: 1185-7.

48. Zweifler J, Hughes S, Schafer S, Garcia B, Grasser A, Salazar L. Are sample medicines hurting the uninsured? J Am Board Fam Pract 2002;15:361-6. 